\title{
Hematopoietic stem/progenitor cells are less prone to undergo apoptosis than lymphocytes despite similar DNA damage response
}

\author{
Matus Durdik ${ }^{1}$, Pavol Kosik ${ }^{1}$, Jana Kruzliakova ${ }^{1}$, Lukas Jakl ${ }^{1}$, Eva Markova ${ }^{1}$ and \\ Igor Belyaev ${ }^{1}$ \\ ${ }^{1}$ Laboratory of Radiobiology, Cancer Research Institute, Biomedical Center, Slovak Academy of Sciences, Bratislava, Slovakia \\ Correspondence to: Igor Belyaev, email: Igor.Beliaev@savba.sk \\ Keywords: imaging flow cytometry, imagestream, flow cytometry, apoptosis, yH2AX
}

Received: December 22, $2016 \quad$ Accepted: March 15, $2017 \quad$ Published: March 22, 2017

Copyright: Durdik et al. This is an open-access article distributed under the terms of the Creative Commons Attribution License 3.0 (CC BY 3.0), which permits unrestricted use, distribution, and reproduction in any medium, provided the original author and source are credited.

\section{ABSTRACT}

Hematopoietic stem/progenitor CD34+ cells (HSPC) give rise to all types of blood cells and represent a key cellular target for origination of leukemia. Apoptosis and repair of DNA double strand breaks (DSB) are vital processes in leukemogenesis. High doses of ionizing radiation are the best known agent that induces leukemia, but less is known about the leukemogenic potential of low doses. While umbilical cord blood (UCB) serves as a valuable source of the HSPC for both research and clinics, the data on DNA damage response and apoptosis in UCB HSPC are very limited. We have studied apoptosis and DSB in the UCB-derived CD34+HSPC and CD34- lymphocytes at different time points post-irradiation with low and therapeutic doses of y-rays. DSB were enumerated with YH2AX foci using imaging flow cytometry. Different stages of apoptosis were analyzed using Annexin/7-AAD assay and YH2AX pan-staining by flow cytometry and imaging flow cytometry, respectively. Our results have consistently shown significantly higher resistance of CD34+ stem/progenitor cells to endogenous and radiation induced apoptosis as compared to CD34- lymphocytes. At the same time, no statistically significant difference was found in DSB repair between HSPC and lymphocytes as enumerated by the yH2AX foci. To conclude, we show for the first time that hematopoietic stem/progenitor cells are less prone to undergo apoptosis than lymphocytes what may be accounted for higher expression of anti-apoptotic proteins in CD34+ cells but was unlikely dealt with DSB repair.

\section{INTRODUCTION}

Human hematopoiesis is initiated from the hematopoietic stem/progenitor cells (HSPC), by their division into more differentiated subtypes. HSPC are known by their multipotency and ability to self-renew. They are characterized by the expression of CD34 and other surface markers in dependence on the differentiation stage [1]. HSPC are responsible for origination of childhood leukemia, which occurs due to accumulation of mutations in hematopoietic stem cells [2]. Unrepaired or misrepaired DNA double strand breaks (DSB) are vital events in formation of various mutations including preleukemic fusion genes. These fusion genes were detected in umbilical cord blood (UCB) [3], which is one of the most available sources of HSPC used both in science and medicine. UCB derived CD34+ cells have been already used for the autologous transplantation in the treatment of childhood leukemia [4]. Phosphorylated form of histone $\mathrm{H} 2 \mathrm{AX}(\gamma \mathrm{H} 2 \mathrm{AX})$ is a generally accepted molecular marker for detecting DSB by enumeration of so-called DNA repair foci [5]. Ionizing radiation (IR) at high doses is one of the best known etiological agents that induce leukemia [6]. The radiosensitivity of different HSPC's subpopulations to high doses has been studied in mice [7] and human [8-11]. While irradiation at high doses is relatively rare, HSPC are often exposed to low doses of IR at the medical examinations such as computer tomography and mammography, at airport security controls and at locations with increased radioactive background. Adverse effects of low doses and their leukemogenic potential are not fully understood, but some links between exposure to low doses and leukemia have been described $[12,13]$. Several studies reported 
significant induction of DSB in human differentiated cells at the low doses comparable with those used at the medical examinations [11, 14-16]. However sensitivity of CD34+ HSPC to low-dose radiation induced apoptosis and DNA damage is not fully assessed.

There are significant differences in expression of crucial regulators of apoptotic pathways between CD34+ HSPC and CD34- UCB cells, which may suggest higher resistance of CD34+ cells to apoptosis [17-19]. The aim of this study was to compare the response of UCB hematopoietic stem/progenitor CD34+ cells and lymphocytes to irradiation with $\gamma$-rays with low and therapeutic doses.

\section{RESULTS}

\section{Apoptosis in CD34+/- UCB cells}

We analyzed fractions of live, early apoptotic and late apoptotic/necrotic (LAN) cells using Annexin/7AAD assay by flow cytometry (Figure 1). This analysis revealed much higher radioresistance of the $\mathrm{CD} 34+$ HSPC (Figure 2). CD marker, time after irradiation and dose were significant factors affecting rate of apoptosis (ANOVA, $p<0.0000001$ ). Interestingly, both CD marker and incubation time were also significant factors for apoptosis in unirradiated samples (ANOVA, $p<0.00002)$. The role of $\mathrm{CD}$ marker was further evaluated by pairwise comparison of data between CD34- and CD34+ cells using two tailed $t$-test. Percentage of live cells was significantly higher in CD34+ population $18 \mathrm{~h}$ after irradiation with 50 and 200 cGy ( $p=0.001$ and 0.005 , respectively) (Figure 2A). This difference in radioresistance between CD34+ HSPC and lymphocytes became even stronger with time after irradiation. At the later stage of apoptosis, $42 \mathrm{~h}$ post irradiation, significantly higher survival of CD34+ cells was observed at all irradiation doses of 5 , 10,50 , and $200 \mathrm{cGy}(p=0.0001,0.0003,0.000001$, and 0.002 , respectively) and even in the unirradiated control cells $(p=0.0004)$. Analysis of the early apoptotic cells (Annexin-V positive/ 7-AAD negative, Figure 2B) has shown significantly lower radiosensitivity of CD34+ cells at the doses 50 and 200 cGy ( $p=0.02$ and 0.001 respectively) $18 \mathrm{~h}$ after irradiation. Analysis of LAN cells (Annexin-V and 7-AAD positive) has confirmed the data obtained by analyzing live cells: (i) significantly higher radioresistance of CD34+ cells in comparison to lymphocytes was detected already $18 \mathrm{~h}$ post-irradiation with 50 cGy ( $p=0.005)$; (ii) CD34+ were more resistant to late apoptosis/necrosis at all doses $0,5,10,50$, and 200 cGy $(p=0.0007,0.002,0.00005,0.00001$, and 0.01 , respectively) as detected $42 \mathrm{~h}$ after irradiation. There was also significantly higher endogenous late apoptosis/ necrosis in the lymphocyte population of the control samples at the beginning of experiments $(p=0.005)$ (Figure 2C). Given all obtained data, we conclude that
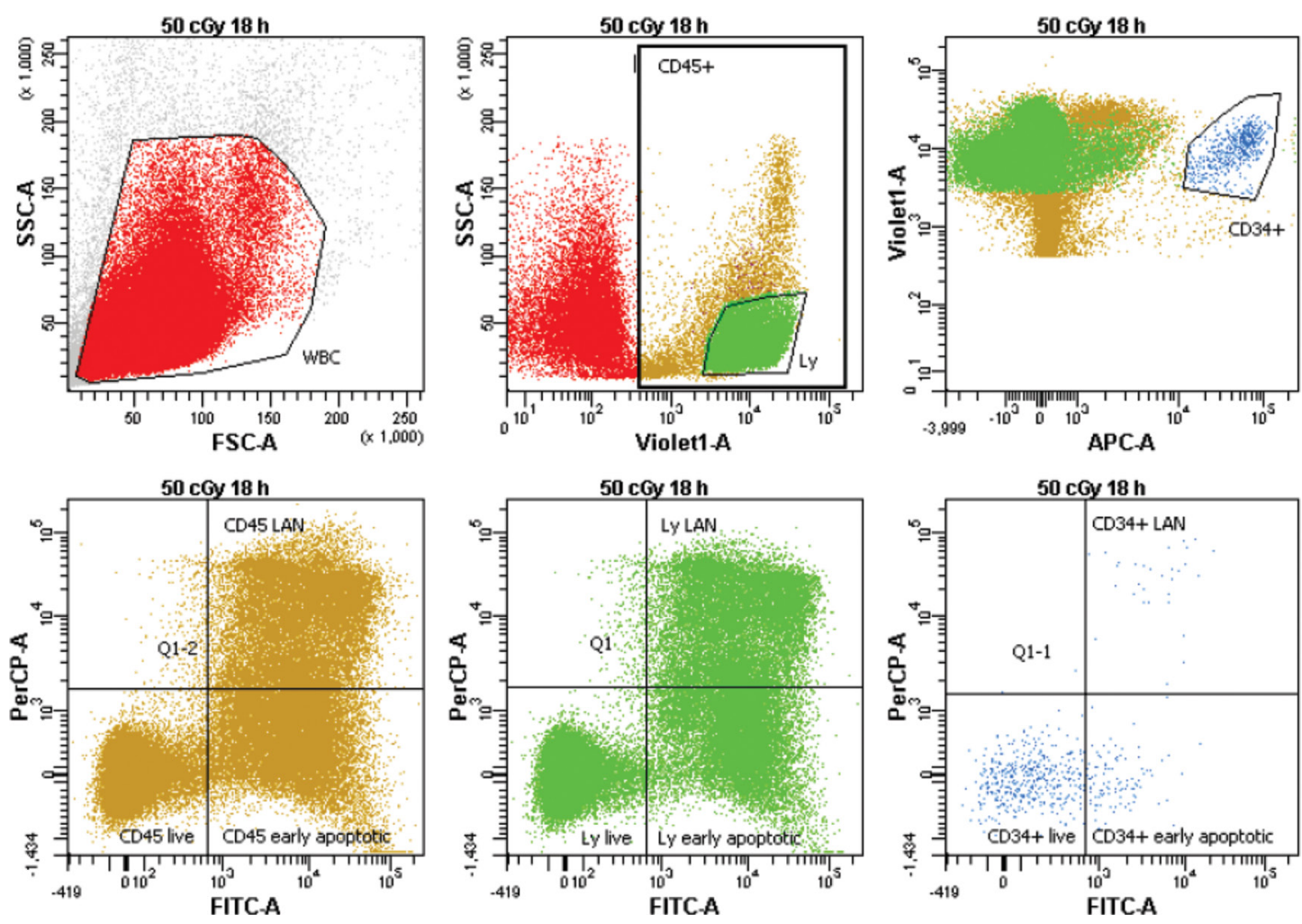

Figure 1: Gating strategy for analysis of apoptosis/necrosis. MNC were gated on FSC vs. SSC. Next, CD45 positive, lymphocytes (Ly) with high expression of CD45 and low SSC, and CD34+ cells with high expression of CD34 were gated. Finally, all subpopulations were analyzed on the Annexin/7-AAD scatter for live, early apoptotic, and late apoptotic/necrotic (LAN) cells. 
UCB hematopoietic stem/progenitor CD34+ cells are more resistant to both radiation-induced and endogenous apoptosis in comparison to CD34- lymphocytes.

\section{DNA repair foci in CD34+/- UCB cells}

Enumeration of $\gamma \mathrm{H} 2 \mathrm{AX}$ foci in CD34+ and CD34populations was performed by the imaging flow cytometry (Figure 3A-3C). In CD34+ cells, we observed maximum level of $\gamma \mathrm{H} 2 \mathrm{AX} 30 \mathrm{~min}$ post irradiation, while $\gamma \mathrm{H} 2 \mathrm{AX}$ foci reached their maximum $2 \mathrm{~h}$ post-irradiation in CD34- cells (Figure 4). However, statistical analysis of all $\gamma \mathrm{H} 2 \mathrm{AX}$ data has not shown any significant difference in DNA damage response between CD34+ HSPC and CD34lymphocytes (ANOVA, $p=0.73$ ). Still there was a trend to lower number of endogenous foci in CD34+ cells ( $t$-test, $p=0.04)$.

\section{$\gamma \mathrm{H} 2 \mathrm{AX}$ pan-staining in CD34+/- UCB cells}

In line with our previous study [10], we analyzed $\gamma \mathrm{H} 2 \mathrm{AX}$ pan-staining cells that are believed to occur in early apoptosis and observed two different types of $\gamma \mathrm{H} 2 \mathrm{AX}$ pan-staining. The first one appeared as staining in vicinity of nuclear membranes, so called apoptotic ring, and the second one resulted in homogeneous staining of the whole nucleus (Figure 5). Analysis of all data for $\gamma \mathrm{H} 2 \mathrm{AX}$ pan-staining has shown significant difference between the CD34+ and CD34- cells (ANOVA, $p=0.02$ ) (Figure 6). Also endogenous level of pan-staining was significantly lower in CD34+ cells after 30 min incubation post sham manipulation ( $t$-test, $p=0.002$ ). These data confirmed the results of flow cytometry analysis, which showed lower rate of endogenous and radiation-induced apoptosis in CD34+ cells (Figure 2).

\section{DISCUSSION}

In this work we have studied apoptosis and DNA damage response induced by low and therapeutic doses of ionizing radiation in UCB derived CD34+ HSPC and lymphocytes. There was some variation between experiments that could be accounted for interindividual variability of probands. In contrast to other studies, we used frozen UCB cells, what may also contribute to this variability. However, the error bars in our study are comparable with other reports for DNA repair foci [9-11, 15], apoptosis [8], and pan-staining [10].

Until now, there is insufficient experimental evidence considering DNA damage response of HSPC

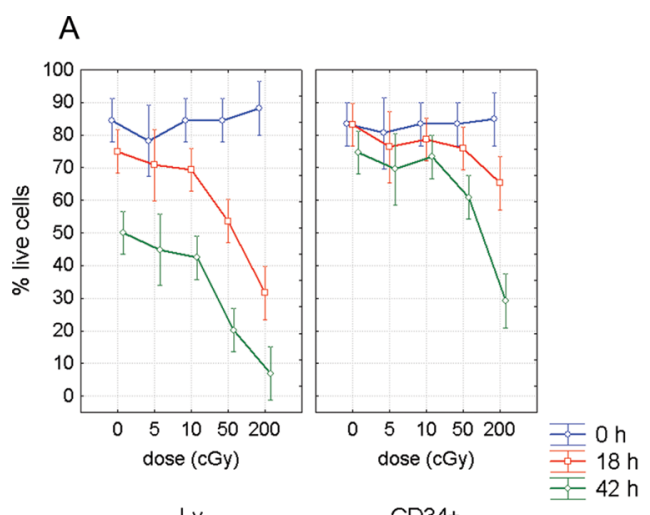

Ly CD34+

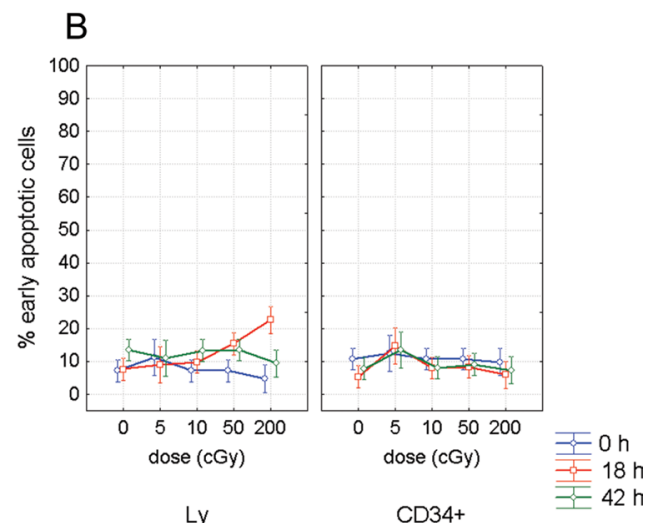

\section{C}

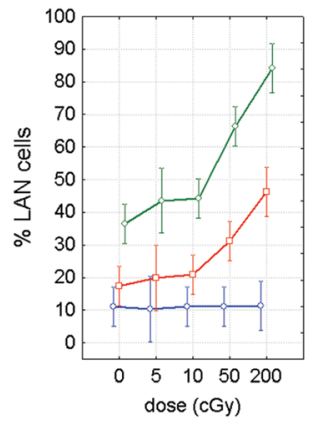

Ly

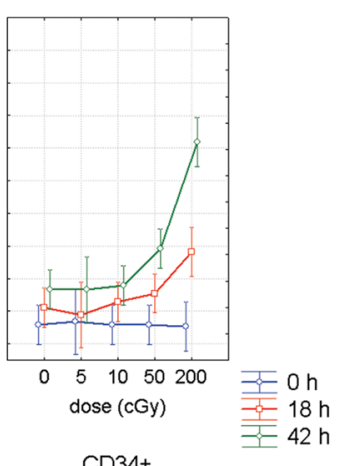

$\mathrm{CD} 34+$

Figure 2: Apoptosis in CD34+/- UCB cells. Figure shows percentage of live (A), early apoptotic (B), and LAN cells (C), in lymphocytes (Ly) and CD34+ cells at different time points post-irradiation with $\gamma$-rays at doses of $0,5,10,50$, and 200 cGy. Mean value and $95 \%$ confidence interval is shown from 11 experiments for 0,10 and $50 \mathrm{cGy}$, from 7 experiments for 2 Gy, and from 4 experiments for 5 cGy. 
to ionizing radiation, especially in comparison of UCB HSPC with more differentiated cell populations. Kraft et al. analyzed DNA damage response in activated CD34+ cells derived from peripheral blood as compared to peripheral blood lymphocytes [20]. In line with our results, these authors did not observe difference in the $\gamma \mathrm{H} 2 \mathrm{AX}$ foci level, but higher level of 53BP1 foci in CD34+ population was found. These data are also in line with the previously published results obtained by our group [10]. Milyavsky et al. compared DNA damage response in different subpopulations of CD34+ cells: termed HSPC (Lin-CD34+CD38-CD45RA-CD90+), Multipotent progenitors (MPP) (Lin-CD34+CD38-CD45RA-CD90-), and progenitors (Lin-CD34+CD38+) [8]. These authors observed higher level of radiation induced $\gamma \mathrm{H} 2 \mathrm{AX}$ foci in the merged HSC/MPP population compared to progenitors $12 \mathrm{~h}$ after $3 \mathrm{~Gy}$ of IR, but they did not compare HSPC with lymphocytes. Vandevoorde et al. enumerated $\gamma \mathrm{H} 2 \mathrm{AX} / 53 \mathrm{BP} 1$ foci in UCB derived CD34+ and T-lymphocytes and also adult T-lymphocytes [9]. No difference was observed between populations $30 \mathrm{~min}$ after low dose X-ray irradiation. However, higher level of $\gamma \mathrm{H} 2 \mathrm{AX} / 53 \mathrm{BP} 1$ foci was found $24 \mathrm{~h}$ post-irradiation with 4 Gy of X-ray in CD34+ population compared with T-lymphocytes. Rube et al. analyzed $\gamma \mathrm{H} 2 \mathrm{AX}$ foci in CD34+ and CD34- cells in correlation with age of
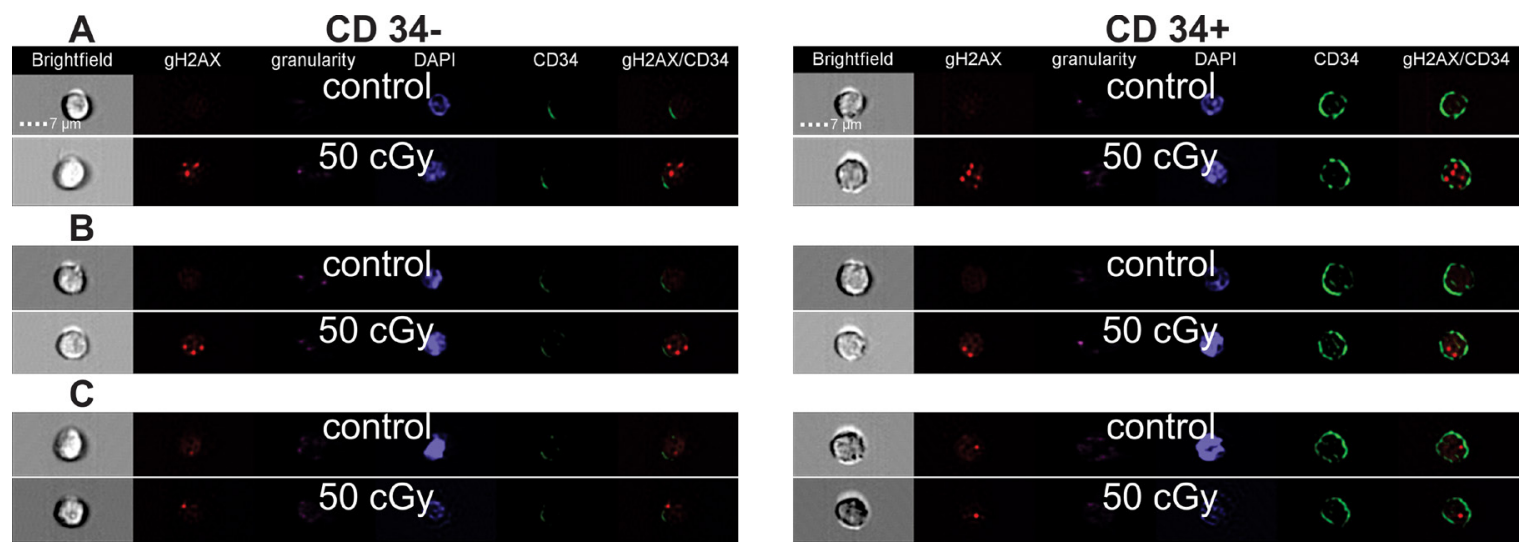

Figure 3: Representative images of cells. Representative images of CD34+ HSPC (right column) and CD34- Ly (left column) acquired by the imaging flow cytometry. The irradiated (50 cGy) and control cells at $30 \mathrm{~min}(\mathbf{A}), 2 \mathrm{~h}(\mathbf{B})$, and $18 \mathrm{~h}(\mathbf{C})$ post-irradiation are shown.
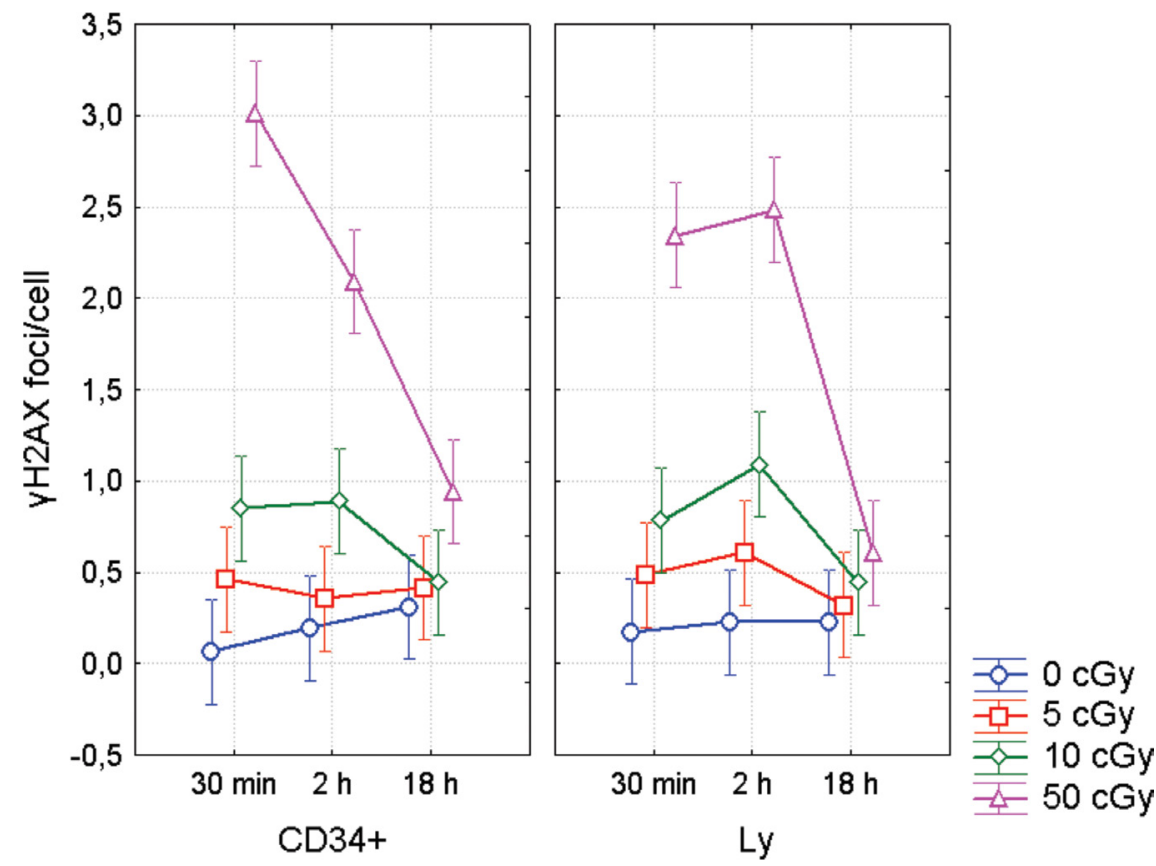

Figure 4: DNA repair foci in CD34+/- UCB cells. $\gamma \mathrm{H} 2 \mathrm{AX}$ foci enumerated by the imaging flow cytometry. UCB MNC were irradiated with $\gamma$-rays $(0,5,10$, and $50 \mathrm{cGy})$ and then lymphocytes (Ly) and CD34+ HSPC were analyzed at different time points (30 min, 2 and $18 \mathrm{~h}$ ) after irradiation. The mean value from 4 experiments along with $95 \%$ confidence interval is shown in each data point. 
probands [11]. The level of $\gamma \mathrm{H} 2 \mathrm{AX}$ endogenous foci observed by these authors in the newborns $(0.1$ for CD34+ and 0.07 for CD34-) is very similar to our results ( 0.06 for CD34+ and 0.17 for CD34-) while the level of radiation induced $\gamma \mathrm{H} 2 \mathrm{AX}$ foci was slightly lower in our study. Based on the results of our present and previous study [10] we concluded that there is no difference in formation of $\gamma \mathrm{H} 2 \mathrm{AX}$ foci between HSPC and lymphocytes. On the other hand, we observed a trend to lower number of endogenous $\gamma \mathrm{H} 2 \mathrm{AX}$ foci in CD34+ cells.

In present work, for the first time, we have studied apoptosis induced by ionizing radiation at low doses in HSPC CD34+ cells in comparison to CD34- cells. Our data obtained with standard flow cytometry have shown much lower rate of apoptosis in CD34+ cells. We have also studied very early stage of apoptosis by analyzing $\gamma \mathrm{H} 2 \mathrm{AX}$ pan-staining with imaging flow cytometry. Two types of $\gamma \mathrm{H} 2 \mathrm{AX}$ pan-staining, complete nuclear staining and socalled apoptotic rings representing ring shaped $\gamma \mathrm{H} 2 \mathrm{AX}$ staining on the periphery of the cell, which co-localize with the TUNEL assay staining [21], were analyzed. In line with our Annexin/7-AAD flow cytometry data, CD34cells have shown significantly higher level of $\gamma \mathrm{H} 2 \mathrm{AX}$ pan-staining as compared to CD34+ cells, thus confirming that HSPC are less prone to undergo endogenous and radiation induced apoptosis. So far, very few studies have analyzed apoptosis in hematopoietic stem cells. Milyavsky et al. compared apoptosis in different subpopulations of CD34+ cells, termed HSPC (Lin-CD34+CD38-CD45RACD90+), MPP (Lin-CD34+CD38-CD45RA-CD90-), and

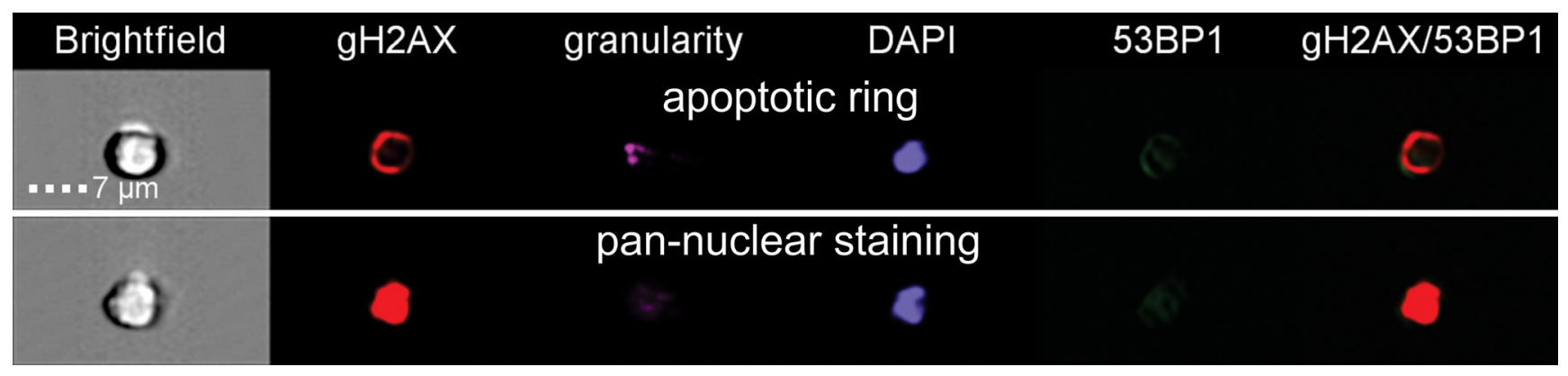

Figure 5: $\gamma \mathbf{H 2 A X}$ pan-staining types. Representative images of two types of $\gamma \mathrm{H} 2 \mathrm{AX}$ pan-staining in UCB cells are shown. The first one was staining only on the circuit of cells, so called apoptotic ring, and the second one was homogeneous pan-nuclear staining of the whole nucleus.
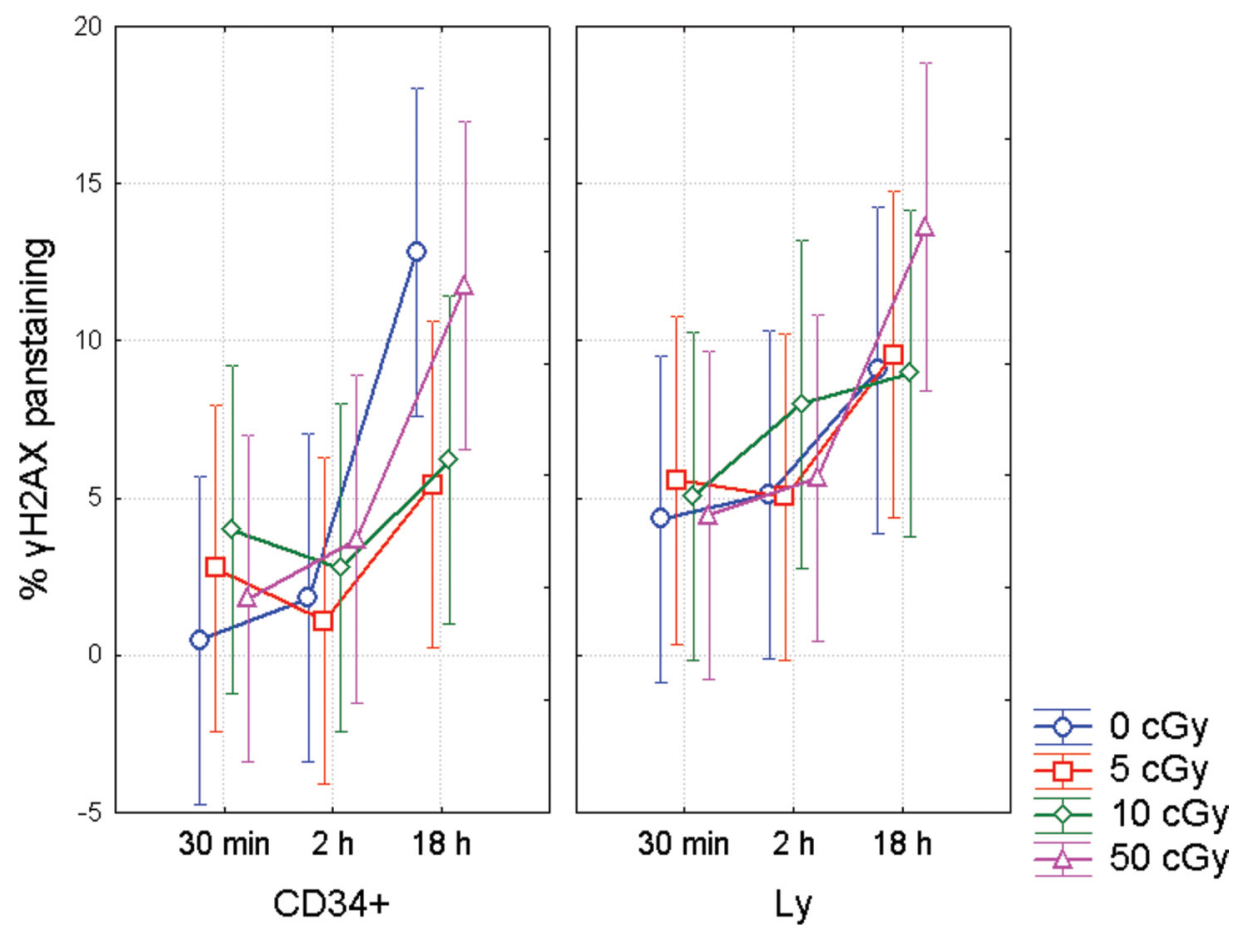

Figure 6: $\gamma$ H2AX pan-staining in CD34+/- UCB cells. $\gamma \mathrm{H} 2 \mathrm{AX}$ pan-staining in UCB lymphocytes (Ly) and CD34+ HSPC from $\mathrm{UCB}$ as analyzed by the imaging flow cytometry. MNC were analyzed in the different time points after irradiation with $\gamma$-rays $(0,5,10$, and 50 cGy). In each data point, mean from 4 experiments along with $95 \%$ confidence interval is shown. 
progenitors (Lin-CD34+CD38+) [8]. Higher percentage of both Annexin and 7AAD positive cells was observed in more primitive CD34+ fractions $18 \mathrm{~h}$ after irradiation. However, these authors did not compare bulk CD34+ population with lymphocytes and effects of low dose irradiation was not studied either. Milyavsky et al. also observed higher expression of apoptosis promoting proteins in CD34+CD90+ population compared to CD34+CD90-. On the other hand, Fukuda et al. reported higher expression of protein survivin, that acts as an inhibitor of apoptosis, in the UCB derived CD34+ cells compared to the CD34population [17]. Merkerova et al. analyzed expression profiles of miRNA clusters in UCB and showed that one of the miRNA clusters, specifically miR-17-92 was highly expressed in the UCB CD34+ cells compare to more differentiated populations [19]. miR-17-92 cluster is associated with low level of TGFBR (transforming growth factor beta receptor) expression and is known to has a role in the inhibition of apoptosis [22]. Moreover, Inoue et al. have shown that transcriptional factor Slug is induced by p53 upon irradiation and then protects the damaged cells from apoptosis by directly repressing $\mathrm{p} 53$ mediated transcription of Puma [23]. This transcriptional factor is preferentially expressed in HSPC, and it shifts the fate of hematopoietic stem and progenitor cells after genotoxic stress toward survival by selectively blocking the apoptotic pathway triggered by p53 [24]. Mohr et al. have shown selective expression of an anti-apoptotic caspase$8 \mathrm{~L}$ isoform, but not pro-apoptotic caspase-8a/b isoforms, in human CD34+ HSPC [18]. Aforementioned publications $[17-19,23,24]$ support our results showing that UCBderived $\mathrm{CD} 34+$ cells are less prone to undergo apoptosis than UCB lymphocytes and accounting this radioresistance for higher expression of anti-apoptotic proteins in the CD34+ cells. Our results are in line with the concept of "apoptosis prone and reluctant" cells, which is useful for practical application by targeting selected cells for example in treatment of cancer with poor curability [25].

\section{MATERIALS AND METHODS}

\section{Chemicals}

Reagent grade chemicals were obtained from SigmaAldrich (St. Louis, Missouri, USA) and Life technologies (Carlsbad, California, USA).

\section{Ethical considerations}

This study has been approved by the Ethics Committee of Children's Hospital in Bratislava.

\section{Cells}

Mononuclear cells (MNC) were extracted from UCB as previously described [10] and stored in liquid nitrogen before experiments. In total, UCB cells from 11 different probands were used. Adherent monocytes were removed by incubation of MNC for $2 \mathrm{~h}$ in RPMI medium supplemented with $10 \% \mathrm{FBS}$ and $100 \mathrm{IU} / \mathrm{ml}$ penicillin, $100 \mu \mathrm{g} / \mathrm{ml}$ streptomycin, at $37^{\circ} \mathrm{C}$ in a $5 \% \mathrm{CO}_{2}$-incubator. Viability of remaining $\mathrm{MNC}$ was higher than $95 \%$ as defined by the Trypan blue exclusion assay.

\section{Irradiation}

The cells were irradiated on ice by $\gamma=$ rays at the dose rate of $0.35 \mathrm{~Gy} / \mathrm{min}$ using a THERATRON ${ }^{\circledR}$ Elite 80 (MDS Nordion, Ottawa, Canada). The irradiated cells were prewarmed to $37^{\circ} \mathrm{C}$ in a water bath and then incubated at $37^{\circ} \mathrm{C}$ in a $\mathrm{CO}_{2}$-incubator till analysis. Control cells were concurrently subjected to the same manipulations as irradiated ones.

\section{Imaging flow cytometry}

UCB cells from four different probands were analyzed by imaging flow cytometry for $\gamma \mathrm{H} 2 \mathrm{AX}$ foci and pan-staining. After incubation for desired period of time, 3-5 million cells were fixed and immunostained with the primary antibody: $\gamma \mathrm{H} 2 \mathrm{AX}$ polyclonal/rabbit at 1:100 dilution (Cell Signalling Technology, Danvers, Massachusetts, USA) as described previously [14]. Afterwards the secondary antibody Alexa Fluor 488 antirabbit 1:200 (Life technologies, Invitrogen Molecular probes, New York, USA) and monoclonal anti-human CD34 APC-conjugated antibody 1:15 (Miltenyi Biotec, Bergisch Gladbach, Germany) were added and incubated for 1 hour at room temperature in the dark. Subsequently, the cells were washed in cold PBS and stained with 3 $\mu \mathrm{M}$ DAPI (Life technologies, Invitrogen Molecular probes). From each sample, at least 15000 cells were captured using the ImageStream ${ }^{\mathrm{X}-100}$ (Amnis Inc., Seattle, Washington, USA) with 60x objective and the extension depth of field 1 (EDF1) to gain the best possible resolution. Four lasers, 405, 488, 656, $785 \mathrm{~nm}$ and CCD camera were used to analyze DNA, $\gamma \mathrm{H} 2 \mathrm{AX}, \mathrm{CD} 34$, granularity and cell morphology, respectively. Images of cells were acquired at the rate of $50-200 \mathrm{cell} / \mathrm{s}$.

Using the IDEAS software, image compensation was performed and IRIF were enumerated in appropriate cells as previously described [14].

\section{Flow cytometry}

UCB cells from eleven different probands were analyzed for apoptosis by flow cytometry. The cells were harvested in different time points after irradiation $(0,18$ and $42 \mathrm{~h}$ ) spun down (100 g/10 min), washed with PBS and resuspended in $100 \mu \mathrm{l}$ of the Annexin kit buffer (Roche, Basel, Switzerland). Cells were then stained with Annexin-V (BD biosciences, San Jose, California, USA), 7-AAD (BD biosciences) and the antibodies against 
the cell surface markers: anti-human CD45-V450 (BD biosciences) and anti-human CD34-APC (Miltenyi Biotec). Samples were then incubated for $20 \mathrm{~min}$ in dark, washed with PBS, spun down, diluted in $200 \mu$ of the Annexin kit buffer and analyzed by the BD FACS Canto II flow cytometer (BD biosciences). Compensation was performed on samples where early apoptotic and LAN cells were present in higher percentage. Single color stained tubes and unstained controls were acquired and compensation was generated automatically by the BD FACSDiva software.

\section{Statistics}

Analysis of variance (ANOVA) was carried out using Statistica 8.0 (Dell software, Round Rock, Texas, United States). Comparison between treatment conditions was performed using two tailed $t$-test. The results were considered significantly different at $p<0.05$

\section{Abbreviations}

DSB-DNA double-strand; breaks $\gamma \mathrm{H} 2 \mathrm{AX}-$ phosphorylated histone 2A family member X; HSC Hematopoietic stem cells; histone $2 \mathrm{~A}$ family member $\mathrm{X}$; HSPC-Hematopoietic stem/progenitor cells; IRIF-ionizing radiation induced foci; Ly-lymphocytes; LAN-late apoptotic and necrotic; MNC-Mononuclear cells; UCBUmbilical cord blood; 7-AAD-7-Aminoactinomycin D

\section{Authors' contributions}

I.B. conceived the experiments; M.D., P.K., J.K., L.J., E.M. conducted the experiments; M.D., P.K., J.K., L.J., I.B. analyzed the results; M.D., I.B. wrote the manuscript.

\section{ACKNOWLEDGMENTS}

We are thankful to Dr. M. Kubes, EurocordSlovakia, Bratislava, Slovak Republic, for providing UCB MNC and Dr. G. Kralik and Dr. K. Kontrisova, St. Elisabeth Cancer Institute, Bratislava, Slovak Republic, for irradiating the cells.

\section{CONFLICTS OF INTEREST}

The authors report no disclosure.

\section{FUNDING}

This work was supported by the Structural Funds of EU (Protonbeam, ITMS: 26220220129), the Slovak Research and Development Agency (APVV-15-0250); and the Vedecká grantová agentúra (VEGA) Grant Agency (2/0109/15, 2/0147/17) of the Slovak Republic. The funders had no role in study design, data collection and analysis, decision to publish, or in the preparation of the manuscript.

\section{REFERENCES}

1. Morrison SJ, Weissman IL. The long-term repopulating subset of hematopoietic stem cells is deterministic and isolatable by phenotype. Immunity. 1994; 1:661-73.

2. Corces-Zimmerman MR, Hong WJ, Weissman IL, Medeiros BC, Majeti R. Preleukemic mutations in human acute myeloid leukemia affect epigenetic regulators and persist in remission. Proc Natl Acad Sci U S A. 2014; 111:2548-53. doi: 10.1073/pnas.1324297111.

3. Skorvaga M, Nikitina E, Kubes M, Kosik P, Gajdosechova B, Leitnerova M, Copakova L, Belyaev I. Incidence of common preleukemic gene fusions in umbilical cord blood in Slovak population. PLoS One. 2014; 9:e91116. doi: 10.1371/journal.pone.0091116.

4. Hayani A, Lampeter E, Viswanatha D, Morgan D, Salvi SN. First report of autologous cord blood transplantation in the treatment of a child with leukemia. Pediatrics. 2007; 119:e296-300. doi: 10.1542/peds.2006-1009.

5. Rogakou EP, Boon C, Redon C, Bonner WM. Megabase chromatin domains involved in DNA double-strand breaks in vivo. J Cell Biol. 1999; 146:905-16.

6. Preston DL, Kusumi S, Tomonaga M, Izumi S, Ron E, Kuramoto A, Kamada N, Dohy H, Matsuo T, Matsui T. Cancer incidence in atomic bomb survivors. Part III. Leukemia, lymphoma and multiple myeloma, 1950-1987. Radiat Res. 1994; 137:S68-97.

7. Meijne EI, van der Winden-van Groenewegen RJ, Ploemacher RE, Vos O, David JA, Huiskamp R. The effects of $\mathrm{x}$-irradiation on hematopoietic stem cell compartments in the mouse. Exp Hematol. 1991; 19:617-23.

8. Milyavsky M, Gan OI, Trottier M, Komosa M, Tabach O, Notta F, Lechman E, Hermans KG, Eppert K, Konovalova Z, Ornatsky O, Domany E, Meyn MS, et al. A distinctive DNA damage response in human hematopoietic stem cells reveals an apoptosis-independent role for p53 in selfrenewal. Cell Stem Cell. 2010; 7:186-97. doi: 10.1016/j. stem.2010.05.016.

9. Vandevoorde C, Vral A, Vandekerckhove B, Philippe J, Thierens H. Radiation Sensitivity of Human CD34(+) Cells Versus Peripheral Blood T Lymphocytes of Newborns and Adults: DNA Repair and Mutagenic Effects. Radiat Res. 2016; 185:580-90. doi: 10.1667/RR14109.1.

10. Vasilyev SA, Kubes M, Markova E, Belyaev I. DNA damage response in CD133 + stem/progenitor cells from umbilical cord blood: low level of endogenous foci and high recruitment of 53BP1. Int J Radiat Biol. 2013; 89:301-9. doi: 10.3109/09553002.2013.754555.

11. Rube CE, Fricke A, Widmann TA, Furst T, Madry H, Pfreundschuh M, Rube C. Accumulation of DNA damage in hematopoietic stem and progenitor cells during human aging. PLoS One. 2011; 6:e17487. doi: 10.1371/journal. pone. 0017487 . 
12. Doll R, Wakeford R. Risk of childhood cancer from fetal irradiation. Br J Radiol. 1997; 70:130-9. doi: 10.1259/ bjr.70.830.9135438.

13. Bithell JF, Stewart AM. Pre-natal irradiation and childhood malignancy: a review of British data from the Oxford Survey. Br J Cancer. 1975; 31:271-87. doi:

14. Durdik M, Kosik P, Gursky J, Vokalova L, Markova E, Belyaev I. Imaging flow cytometry as a sensitive tool to detect low-dose-induced DNA damage by analyzing 53BP1 and gammaH2AX foci in human lymphocytes. Cytometry A. 2015; 87:1070-8. doi: 10.1002/cyto.a.22731.

15. Roch-Lefevre S, Mandina T, Voisin P, Gaetan G, Mesa JE, Valente M, Bonnesoeur P, Garcia O, Roy L. Quantification of gamma-H2AX foci in human lymphocytes: a method for biological dosimetry after ionizing radiation exposure. Radiat Res. 2010; 174:185-94. doi: 10.1667/RR1775.1.

16. Lobrich M, Rief N, Kuhne M, Heckmann M, Fleckenstein J, Rube C, Uder M. In vivo formation and repair of DNA double-strand breaks after computed tomography examinations. Proc Natl Acad Sci U S A. 2005; 102:89849. doi: 10.1073/pnas.0501895102.

17. Fukuda S, Pelus LM. Regulation of the inhibitor-ofapoptosis family member survivin in normal cord blood and bone marrow CD34(+) cells by hematopoietic growth factors: implication of survivin expression in normal hematopoiesis. Blood. 2001; 98:2091-100.

18. Mohr A, Zwacka RM, Jarmy G, Buneker C, Schrezenmeier H, Dohner K, Beltinger C, Wiesneth M, Debatin KM, Stahnke K. Caspase-8L expression protects CD34+ hematopoietic progenitor cells and leukemic cells from CD95-mediated apoptosis. Oncogene. 2005; 24:2421-9. doi: 10.1038/sj.onc.1208432.
19. Merkerova M, Vasikova A, Belickova M, Bruchova H. MicroRNA expression profiles in umbilical cord blood cell lineages. Stem Cells Dev. 2010; 19:17-26. doi: 10.1089/ scd.2009.0071.

20. Kraft D, Rall M, Volcic M, Metzler E, Groo A, Stahl A, Bauer L, Nasonova E, Salles D, Taucher-Scholz G, Bonig H, Fournier C, Wiesmuller L. NF-kappaB-dependent DNA damage-signaling differentially regulates DNA doublestrand break repair mechanisms in immature and mature human hematopoietic cells. Leukemia. 2015; 29:1543-54. doi: 10.1038/leu.2015.28.

21. Solier S, Pommier Y. The nuclear gamma-H2AX apoptotic ring: implications for cancers and autoimmune diseases. Cell Mol Life Sci. 2014; 71:2289-97. doi: 10.1007/s00018013-1555-2.

22. Mendell JT. miRiad roles for the miR-17-92 cluster in development and disease. Cell. 2008; 133:217-22. doi: 10.1016/j.cell.2008.04.001.

23. Inoue A, Seidel MG, Wu W, Kamizono S, Ferrando AA, Bronson RT, Iwasaki H, Akashi K, Morimoto A, Hitzler JK, Pestina TI, Jackson CW, Tanaka R, et al. Slug, a highly conserved zinc finger transcriptional repressor, protects hematopoietic progenitor cells from radiation-induced apoptosis in vivo. Cancer Cell. 2002; 2:279-88.

24. Oguro H, Iwama A. Life and death in hematopoietic stem cells. Curr Opin Immunol. 2007; 19:503-9. doi: 10.1016/j. coi.2007.05.001.

25. Blagosklonny MV. Prospective strategies to enforce selectively cell death in cancer cells. Oncogene. 2004; 23:2967-75. doi: 10.1038/sj.onc.1207520. 